\title{
Mídia, UPPs e megaeventos: estratégias discursivas de legitimação de uma política de segurança pública ${ }^{1}$
}

\author{
Media, UPP and mega events: discursive strategies of legitimizing a public \\ security policy \\ Medios, UPP y mega eventos: estrategias discursivas de la legitimación de una \\ política de seguridad pública
}

Pedro Barreto Pereira ${ }^{2}$

\section{Resumo}

Entre 2007 e 2016, o Rio de Janeiro ingressou no circuito dos megaeventos esportivos internacionais. A partir de então, as três esferas governamentais vêm promovendo uma série de políticas públicas de modo a reconfigurar estética e urbanisticamente a cidade. Discursivamente, a estratégia envolve a refundação da "Cidade Maravilhosa" e a exaltação dos aludidos atributos pitorescos do carioca, tais como simpatia, irreverência e hospitalidade. Além dos já conhecidos ícones, que remetem a uma cultura do hedonismo, como samba, carnaval e futebol, a favela torna-se outro elemento a ser incorporado ao branding carioca. Para atrair turistas, investidores e atender às demandas de lei e ordem da elite carioca, contudo, o projeto em curso conta, fundamentalmente, com a ocupação policial dessas mesmas favelas: as UPPs (Unidades de Polícia Pacificadora), que, ao mesmo tempo em que permitem o acesso das elites a áreas até então consideradas violentas, promovem a migração dos moradores de menor poder aquisitivo para bairros mais afastados e precários. A lógica em vigor passa a ser então a do consumo como pré-requisito da cidadania: o acesso à "Cidade Maravilhosa", tão cobiçada por todo o mundo, fica restrito a uma pequena parcela da população.

Palavras-chave: Mídia. Segurança. Favela. Cidade.

\begin{abstract}
Between 2007 and 2016, the Rio de Janeiro joined the circuit fainter nationals ports mega events. Since then, the three level sof government have been promoting a series of public policies to reconfigure aesthetics and urban planning the city. Discursively, the strategy involves there-foundation of the "Wonderful City" and the exaltation of the Rio alluded pictures que attributes such as friendliness, irreverence and hospitality. Besides the already known icons, which refer to a culture of he donism, like samba, carnival and football, the favela become san other element to be incorporated into the "carioca branding". To attract tourists, investors and attend the law and order the carioca elite's demands, however,
\end{abstract}

\footnotetext{
${ }^{1}$ Este texto é uma etapa intermediária de pesquisa de Doutorado desenvolvida no Programa de Pós-Graduação em Comunicação e Cultura da Universidade Federal do Rio de Janeiro (UFRJ). Uma versão resumida foi apresentada no Grupo de Pesquisa Información, comunicación y discurso: viejas y nuevasmediaciones, do VIII Encuentro Internacional de Investigadores y Estudiosos de laInformación y laComunicación e do IX Congreso Internacional de la Unión Latina de la Economía Política de laInformación, laComunicación y la Cultura (ULEPICC), realizado entre 7 e 11 de dezembro de 2015, na Universidade de La Habana, Cuba.

${ }^{2}$ Doutorando e mestre pelo Programa de Pós-Graduação em Comunicação da Universidade Federal do Rio de Janeiro (UFRJ), Brasil, Rio de Janeiro. E-mail: ppbarreto@gmail.com.
}

Comun. \& Inf., Goiânia, GO, v. 18, n. 02, p. 180-197, jul./dez. 2015 
the ongoing project has as main support the police occupation of those lums: the UPPs (Police Units Pacification), which, while that allow access to the elite areas hither to considered violent, promote the migration of resident so flower income to more remote and poor neighborhoods. The guideline in force then becomes the consumption as a prerequisite of citizenship: access to the "Marvelous City", so coveted around the world, is restricted to a small portion of the population.

Key-words: Media. Security. Slums. City.

\section{Resumen}

Entre 2007 y 2016, Río de Janeiro se unió al circuito de grandes eventos deportivosinternacionales. Desde entonces, lostres niveles de gobiernohanestado promoviendo una serie de políticas públicas para volver a configurar laestética y laplanificación urbana de laciudad. Discursivamente, laestrategia consiste enlarefundación de la "CiudadMaravillosa" y laexaltación delosaludidos atributos pintorescos como laamabilidad, la irreverencia y lahospitalidad. Además de losiconosyaconocidos, que se refieren a una cultura del hedonismo, como la samba, el carnaval y elfútbol, la favela se convierteenun elemento más para ser incorporado ala marca Rio. Para atraer a los turistas, los inversores y cumplirconlas demandas de laley y elorden delaélite carioca, sin embargo, elproyectoen curso cuenta fundamentalmente conlaocupación policial de esasfavelas: la UPP (Unidades de Policía Pacificadora), que, aunque que permitenelacceso a las zonas de élite hasta entonces considerados violentos, promover lamigración de los residentes de bajosingresos a losbarrios más pobres y remotos. La lógica en vigor se convierteentoncesenel consumo como un requisito previo de laciudadanía: elacceso a la "CiudadMaravillosa", por locodiciadoen todo el mundo, se limita a una pequeña parte de lapoblación.

Palabras-clave: Medios de comunicación. Seguridad. Favelas. Ciudad.

\section{INTRODUÇÃO}

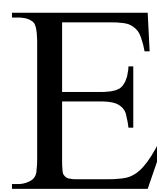

m 2007, a partir da escolha do Rio de Janeiro como sede da Copa do Mundo de 2014 e dos Jogos Olímpicos de 2016, teve início uma série de intervenções urbanas promovida pelas esferas federal, estadual e municipal. Era preciso refundar a genuína "Cidade Maravilhosa", que perdera sua pujança econômica a partir dos anos 1960, com a mudança da capital federal para Brasília, o êxodo de investidores, mas, principalmente, pela desatenção e má gestão pública que se abateram sobre o estado do Rio de Janeiro e sua capital. Para garantir novamente a credibilidade dos organismos internacionais, seus financiadores e visitantes estrangeiros, era fundamental reconstruir a identidade da cidade, reforçar os seus pontos positivos e corrigir (em pouquíssimo tempo) as mazelas de décadas de descaso e abandono.

Em ação conjunta, os três níveis de governo implementaram diversas modificações urbanísticas na cidade, de forma a construir equipamentos esportivos, mobilidade e infraestrutura, por meio de desapropriações e outras medidas governamentais que, muitas vezes, careceram de

Comun. \& Inf., Goiânia, GO, v. 18, n. 02, p. 180-197, jul./dez. 2015

Caderno Casadinho Procad UFG-UFRJ 
diálogo com o conjunto da população ${ }^{3}$. Para garantir o transporte ágil durante os megaeventos, o poder público criou corredores expressos de ônibus, ligando as zonas oeste e norte do Rio, os chamados Bus Rapid Transit (BRTs). Sua execução, entretanto, foi realizada ao custo da remoção de, aproximadamente, 10 mil moradores de favelas ou pequenos bairros localizados no trajeto do BRT, de acordo com dados do Comitê Popular Rio e Olimpíadas ${ }^{4}$. Outra alteração substancial foi a criação do Campo de Golfe Olímpico, construído sobre uma área de preservação ambiental na zona oeste da cidade.

Já o poder público municipal atuou, desde o início da gestão do atual prefeito Eduardo Paes, em consonância com o discurso reforçado e consolidado, ao longo de décadas, pelos principais veículos de comunicação do país. Discurso este que reivindica a aplicação vigorosa da lei e da ordem em seu espaço urbano. Em 2008, a eleição à Prefeitura Municipal foi precedida por uma série de reportagens do jornal O Globo denominada Ilegal, e daí?, que alertava para o risco ao ordenamento urbano e à segurança pública que pessoas em situação de rua, vendedores ambulantes, estacionamentos irregulares, entre outros casos, poderiam trazer. Uma das primeiras iniciativas do prefeito foi a criação da política que denominou Choque de Ordem, que visava a acabar com os sintomas de desordem e ilegalidade diagnosticados pelo jornal, explicitando assim, a consonância entre o discurso midiático e as ações do poder público municipal.

Por parte do governo do Estado, então sob o comando de Sérgio Cabral Filho, a principal iniciativa foi a criação das Unidades de Polícia Pacificadora (UPPs), que se constitui na ocupação permanente de determinadas favelas da capital pelas forças de Segurança Pública 5 . Garantir a segurança dos turistas e dos moradores das classes média e alta passara a ser prioridade. Haja vista que o Rio de Janeiro, desde meados da década de 1980, é retratado nacional e internacionalmente pelos meios de comunicação como uma cidade insegura, devido ao confronto entre policiais e comerciantes varejistas de entorpecentes que, cada vez mais frequentemente, vitimavam civis. A primeira UPP implantada foi a do Morro Santa Marta, em Botafogo,

\footnotetext{
3 Para a reforma do Maracanã, por exemplo, houve confrontos com os moradores despejados da Favela do Metrô, próxima à Mangueira. Na obra do estádio, foram gastos cerca de $\mathrm{R} \$ 1,3$ bilhão e sua gestão foi entregue a um consórcio privado de empresas, através de uma licitação, até hoje, envolta em suspeitas quanto à sua lisura.

4 Disponível em: <http://agenciabrasil.ebc.com.br/geral/noticia/2014-12/comite-critica-reforma-do-maracana-eremocao-de-familias-no-periodo-da-copa $>$. Acesso em: 24 mai. 2015.

${ }^{5}$ Além da Polícia Militar do Estado do Rio de Janeiro (PMERJ), em casos, como o Complexo do Alemão e da Maré, tropas do Exército, da Marinha e da Força Nacional foram utilizadas para acabar com a resistência de grupos armados que detinham o controle dessas comunidades através do poderia bélico.
}

Comun. \& Inf., Goiânia, GO, v. 18, n. 02, p. 180-197, jul./dez. 2015

Caderno Casadinho Procad UFG-UFRJ 
considerado, nos anos 1980, atemorizante aos moradores daquele bairro. Devido à sua geografia, que facilita o policiamento sem que grupos criminosos entrem ou saiam da localidade, a população reduzida - se comparada a de outras favelas da cidade -, e dos investimentos realizados em ações sociais, o Santa Marta foi considerado pelo secretário de Segurança Pública, José Mariano Beltrame, como "policiamento modelo" a ser seguido nas futuras ocupações. A instalação foi anunciada com exaltação pelo jornal O Globo "Dona Marta livre dos bandidos"7, proclamava o periódico.

Até outubro de 2015, 38 favelas receberam UPPs. Em sua quase totalidade, as ocupações estão localizadas nas zonas sul, norte e centro da cidade (circunscritas ao "cinturão de segurança do entorno financeiro do Rio"), próximas a equipamentos esportivos utilizados nos megaeventos, ou em áreas próximas a vias de grande tráfego ${ }^{8}$. Inicialmente, as ocupações foram bemsucedidas, com a redução do índice de criminalidade, devido ao fím do poderio bélico dos grupos armados de comerciantes varejistas de entorpecentes e do consequente fim de confrontos armados com os agentes policiais. Além de diminuírem o número de vítimas decorrentes dos tiroteios e de criarem uma interlocução estatal para a mediação de conflitos, as UPPs possibilitaram ainda que moradores da chamada "cidade formal", ou "do asfalto", passassem a frequentar as favelas, em busca de entretenimento pouco habitual até então, preços mais razoáveis de imóveis e mesmo oportunidades de bons negócio. Ponto positivo, na visão do secretário Beltrame, que, em depoimento ao filme "5x Pacificação" (2012), afirmou:

Não é só o Estado que tem que entrar lá, o cidadão também tem que entrar lá. Ele tem que começar a ver que ele pode entrar lá, transitar, abrir algum negócio, comer lá dentro, fazer alguma compra, enfim. A estratégia é justamente misturar

\footnotetext{
${ }^{6}$ ARAÚJO, V. Unidade da PM em prédio de creche gera protestos no Morro Dona Marta. O Globo. Rio de Janeiro, 28 de novembro de 2008, p. 15.

${ }^{7}$ WERNECK, A., DAMASCENO \& N., AUTRAN, P. Dona Marta livre dos bandidos. Após quase duas semanas de ocupação pela PM, todas as ‘bocas de fumo' estão fechadas. O Globo, editoria Rio. Rio de Janeiro, 3 de dezembro de 2008, p. 12.

${ }^{8}$ As 38 UPPs estão localizadas nas seguintes comunidades: Zona Sul: Santa Marta, Babilônia e Chapéu Mangueira, Pavã-Pavãozinho e Cantagalo, Tabajaras e Cabritos, Escondidinho e Prazeres, Rocinha, Vidigal, Cerro-Corá. Zona Norte: Borel, Formiga, Andaraí, Salgueiro, Turano, São João, Matriz e Quieto, Macacos, Mangueira, Nova Brasília, Fazendinha, Adeus e Baianinha, Alemão, Chatuba, Fé e Sereno, Parque Proletário, Vila Cruzeiro, Jacarezinho, Manguinhos, Barreira do Vasco e Tuiutí, Caju, Arará e Mandela, Lins, Camarista Meier. Zona Oeste: Cidade de Deus, Batan, Vila Kennedy. Centro: Providência, Coroa, Fallet e Fogueteiro, São Carlos. Baixada Fluminense: Mangueirinha (Duque de Caxias). Disponíveis em: <http://www.upprj.com/index.php/historico $>$. Acesso em: 7 jul 2015.

${ }^{9}$ Ainda que a perspectiva da "cidade partida", em que favela e "asfalto" são percebidas como espaços distintos, seja fortemente questionável, neste estudo sobre representações sociais, ela nos parece aplicável.
}

Comun. \& Inf., Goiânia, GO, v. 18, n. 02, p. 180-197, jul./dez. 2015 
isso, que a sociedade se intere daquelas áreas, que a iniciativa privada invista naquelas áreas. ${ }^{10}$

Se por um lado, o secretário diz atuar em favor de uma integração da cidade, que possibilite a entrada de visitantes e de capital econômico nas favelas, por outro, o poder público negligencia quanto ao aumento do custo de vida, que acaba por impelir a saída de moradores pela absoluta falta de condições materiais para continuar residindo em uma favela inflacionada. Desta maneira, o destino dessas pessoas tem sido bairros mais afastado de sua origem, distante de suas famílias, amigos, local de trabalho e onde, possivelmente, a oferta de serviços de saúde, educação, transporte e comércio é deficiente. Além disso, a concorrência desigual entre os pequenos comerciantes e os grandes empresários, agora investindo nas favelas, tem resultado na falência daqueles. Outro fator que tem levado ao questionamento das UPPs é que, se em um primeiro momento, as ocupações lograram êxito em acabar com os conflitos entre policiais e grupos armados de comerciantes varejistas de entorpecentes, sete anos após a implantação da primeira UPP, os tiroteios voltaram a ocorrer em diversas comunidades. Ademais, a convivência entre agentes da Polícia e moradores nunca foi, de fato, pacífica. O assassinato do pedreiro Amarildo, na Rocinha, do dançarino DG, no Pavão-Pavãozinho, e do jovem Eduardo, no Morro da Providência, todos com envolvimentocomprovado de policiais militares com atuação nas UPPs, são os mais conhecidos, mas não os únicos.

\section{METODOLOGIA}

Este trabalho é um esforço de transição entre a dissertação de Mestrado "Segurança para quem? O discurso midiático sobre as Unidades de Polícia Pacificadora" (PEREIRA, 2012) e a tese de doutorado em desenvolvimento sobre o mesmo tema, com seu corpus de pesquisa ampliado e atualizado. Para fins metodológicos, recorreremos aos conceitos de agenda setting (ou agendamento) e frame analisys (ou enquadramento), utilizados por Beckett (1997), que contribuiu para a análise das reportagens e originou as investigações que têm continuidade na presente pesquisa. Nossa proposta é analisar as notícias em questão a partir da ótica dos conceitos Agenda Setting (agendamento) e Frame Analisys (enquadramento). O primeiro diz respeito ao que será abordado na mídia, a partir da seleção de determinados temas em detrimento de outros.

${ }^{10}$ Depoimento em '5 x Pacificação (Barcellos, Felha, Novais, Vidigal, 2012), em 52’43”.

Comun. \& Inf., Goiânia, GO, v. 18, n. 02, p. 180-197, jul./dez. 2015 
De acordo com a abordagem de Hohlfeldt (2001), “o agendamento somente ocorrerá de maneira eficiente quando houver um alto nível de percepção de relevância para o tema e, ao mesmo tempo, um grau de incerteza relativamente alto em relação ao domínio do mesmo" (HOHLFELDT, 2001, p. 199).

Já o segundo é a perspectiva através da qual aqueles temas previamente definidos serão abordados. Em um artigo sobre a forma como a mídia aborda as pautas do movimento feminista, entre os anos 1950 e 1990, Terkildsen e Schnell (1997) analisam como as decisões editoriais de veículos impressos e audiovisuais influenciam a opinião dos leitores e o próprio debate político acerca do tema. Segundo os dados analisados, foram cinco os enquadramentos identificados: direitos políticos, direitos econômicos, feminismo, antifeminismo e papéis de gênero. No entanto, apenas dois deles - feminismo e direitos econômicos - representaram $75 \%$ da cobertura midiática e ambos exerceram um impacto negativo nas questões de gênero e no apoio aos direitos das mulheres. Apenas o framedireitos políticos, utilizado em $10 \%$ das matérias publicadas, teve um impacto positivo no apoio a políticas de igualdade. A partir desta conclusão, as autoras observam que a influência da mídia na opinião do público - que, por sua vez elege os legisladores - se dá não apenas pela seleção dos assuntos escolhidos como prioridade da "agenda pública", como também, ao hierarquizar as questões mais importante, acaba por negligenciar outras. Ou ainda, “o verdadeiro poder da mídia está em dizer ao público em que questões pensar, bem como a forma de pensar sobre essas questões" (TERKILDSEN \& SCHNELL, 1997: p. 894).

De acordo com a abordagem metodológica de Beckett (1997), as reportagens sobre crime podem ser classificadas em quatro categorias, a partir de elementos narrativos que indicam tendências a: lei e ordem, cidadania, liberdades civis sob ataque e pobreza como causa do crime. Propomos também analisar o que denominamos clivagens ideológicas: as UPPs são representadas como um benefício à população da favela ou do "asfalto"? São parte de estratégia de um Estado de Direito ou um Estado Policialesco? São integrantes de uma política permanente e consolidada ou frágil e temporária? E ainda, se as fontes citadas tinham algum vínculo com o Estado (governador, secretário, policial, juiz etc.) ou não.

$\mathrm{Na}$ dissertação de Mestrado "Segurança para quem? O discurso midiático sobre as Unidades de Polícia Pacificadora" (PEREIRA, 2012), a maior parte das matérias sobre UPPs publicadas pelo jornal $\mathbf{O}$ Globo privilegiou o enquadramento lei e ordem, que justifica a 
violência cometida pela Polícia durante as ocupações através do argumento da pacificação e da guerra ao crime. Outrossim, das 219 fontes consultadas, 142 (65\%) são, de alguma maneira, vinculadas ao Estado (prefeito, governador, secretário de Segurança, juiz, chefe de Polícia, soldado etc.). As não estatais, quando ouvidas, referendavam, em grande parte, o discurso daquelas. Apenas 13 fontes não estatais apresentavam depoimentos contrários à instalação das UPPs ou à atuação de policiais. Ainda assim, em todas as oportunidades, elas foram confrontadas a declarações de autoridades do Estado. Ademais, as UPPs são, para o jornal O Globo, uma política permanente e consolidada, garantidora de um estado democrático de direito e dirigida a moradores da favela. Também foram analisados veículos comunitários que abordavam a questão das UPPs. Nesses, os enquadramentos mais frequentemente encontrados foram aqueles que denunciavam o desrespeito às liberdades civis dos moradores. As fontes mais comumente identificadas foram as não estatais. Quanto às clivagens ideológicas, as UPPs são apresentadas como uma política de continuidade duvidosa, voltada a moradores "do asfalto" e garantidora de um estado policialesco.

A proposta deste artigo é apresentar os resultados parciais encontrados até aqui e apontar perspectivas futuras. Na pesquisa de doutorado em curso, pretendemos atualizar os dados referentes às notícias publicadas no jornal $\mathbf{O}$ Globo - periódico de maior circulação na cidade e no estado do Rio de Janeiro e segundo maior do país - sobre as UPPs, nos anos de 2012 até 2015, incluindo as favelas onde as ocupações foram iniciadas recentemente.

Nunca é demais lembrar que este trabalho está circunscrito e limitado ao campo comunicacional e, por isso, não pretende atestar a validade ou não de políticas públicas em curso, em que diversos atores sociais estão envolvidos. Apenas se propõe a contribuir apresentando mais um ponto de vista, mais uma perspectiva de análise para a complexidade do momento atual.

\section{PRODUZINDO A "CIDADE MARAVILHOSA"}

O ideário da "Cidade Maravilhosa" perpassa tanto o discurso midiático quanto as iniciativas governamentais em direção a um projeto de cidade que remete aos dois possíveis mitos de origem da alcunha hoje internacionalmente conhecida: tanto o livro " $\mathrm{La}$ VilleMerveilleuse", de 1913, da poetisa francesa Jeanne CatulleMendès (ALMEIDA; NAJAR, 2012, p. 120-121), quanto a marcha carnavalesca "Cidade Maravilhosa", composta em 1935 por

Comun. \& Inf., Goiânia, GO, v. 18, n. 02, p. 180-197, jul./dez. 2015 
André Filho e Silva Sobreira, enaltecem as belezas naturais da cidade e o fascínio exercido nos visitantes. Em sua obra, Mendès descreve uma visita ao Rio de Janeiro nos poemas "Arrivedans La Baie de Guanabara", "Salut" e "Adieu". "Todos exaltam acidade esplendorosa, a beleza das paisagens da natureza, a luz do céu azul claro, o ar fresco e os momentos de contemplação" (ALMEIDA; NAJAR, 2012, p. 120). A segunda hipótese é o artigo "Os sertanejos", de Coelho Neto, publicado na "página 03, do jornal 'A Notícia', edição de 29.11.1908" (CAMPOS, 1965, p. 76 e Milton Teixeira apud DE ALMEIDA e NAJAR, 2012: p. 121). A expressão dá nome ao programa "Crônicas da Cidade Maravilhosa", na Rádio Mayrink Veiga, apresentado por César Ladeira. Em 1934, André Filho, com arranjo de Silva Sobreira, compõe a marcha carnavalesca "Cidade Maravilhosa", tornada mundialmente conhecida pela voz de Aurora Miranda, e até hoje executada em blocos, cordões e bailes carnavalescos. Já em 1960, o vereador Salles Neto aprova "a Lei no. 5 que determina 'adotada como marcha oficial desta cidade do Rio de Janeiro, respeitando os respectivos direitos autorais, ex vi da legislação anterior, a marcha "Cidade Maravilhosa", de autoria do compositor André Filho" (COSTA, 2001, p.143 apud DE ALMEIDA e NAJAR, 2012: p. 122).

Os anos 1950 ajudaram a consolidar esta identidade a partir da Bossa Nova, do título mundial de futebol em 1958, do Cinema Novo e de outros episódios que levaram o Brasil e o Rio de Janeiro a alcançar uma repercussão midiática em escala mundial. Para Santos (1998), aquele era o ano "que não devia terminar", dada a reunião de fatos, considerados por ele, relevantes para expurgar de vez o conhecido "complexo de vira-latas" (RODRIGUES, 1993, p. 51).

"O brasileiro deixava de ser um vira-lata entre os homens e o Brasil um vira-lata entre as nações. Não havia mais motivos para chorar o gol arrasador do uruguaio Ghiggia, oito anos antes, ou as duas polegadas da Marta Rocha. Café pequeno, xaveco. A taça do mundo era nossa, assim como a Marilyn Maxwell, atriz americana que veio pular o carnaval aqui e o Jorginho Guinle, crau, botou-lhe a bola no fundo da rede, marcando mais um golaço para as nossas cores. A palavra orgulho entrou na moda e, será coincidência?, foi justo aí que tudo passou a ser bárbaro. Era bárbaro, por exemplo, andar na pioneira escada rolante da Sears. Era bárbaro ser do mesmo país da Maria Ester Bueno, que no mês seguinte ao dos canarinhos foi campeã de duplas em Wimblendon.” (SANTOS, 1998, p. 15)

As décadas seguintes, entretanto, foram áridas para a população do Rio de Janeiro. Com a transferência da capital da República para Brasília, em 1960, calcula-se que a cidade tenha perdido cerca de 120 mil empregos públicos, além da natural fuga de investimentos privados. O

Comun. \& Inf., Goiânia, GO, v. 18, n. 02, p. 180-197, jul./dez. 2015

Caderno Casadinho Procad UFG-UFRJ 
crescimento da demanda pelo consumo de cocaína nas classes alta e média, nos anos 1970, e, consequentemente, da repressão ao comércio varejista de entorpecentes nas favelas cariocas acentuada a partir do início do governo Moreira Franco, em 1986 - contribuiu sobremaneira para macular a alcunha criada e cultivada nas décadas precedentes.

A partir de 2007, com a realização dos Jogos Pan-Americanos na cidade, inicia-se a tentativa de resgate da imagem da cidade. Nas gestões Sérgio Cabral Filho (estadual) e Eduardo Paes (municipal), por meio de vigorosos patrocínios empresariais e aparato midiático, os antigos atributos da cidade são frequentemente exaltados, de forma a configurar esteticamente a capital fluminense aos megaeventos esportivos internacionais que se avizinham. Em 2015, ao comemorar 450 anos, a Prefeitura instala, na fachada de um grande shopping na zona sul da cidade, um painel publicitário em louvor às características consideradas como genuínas da população carioca, resumidos em um único substantivo (Figura 1).

Figura 1 - "Viva a carioquice". Painel instalado na fachada de um shopping da zona sul do Rio

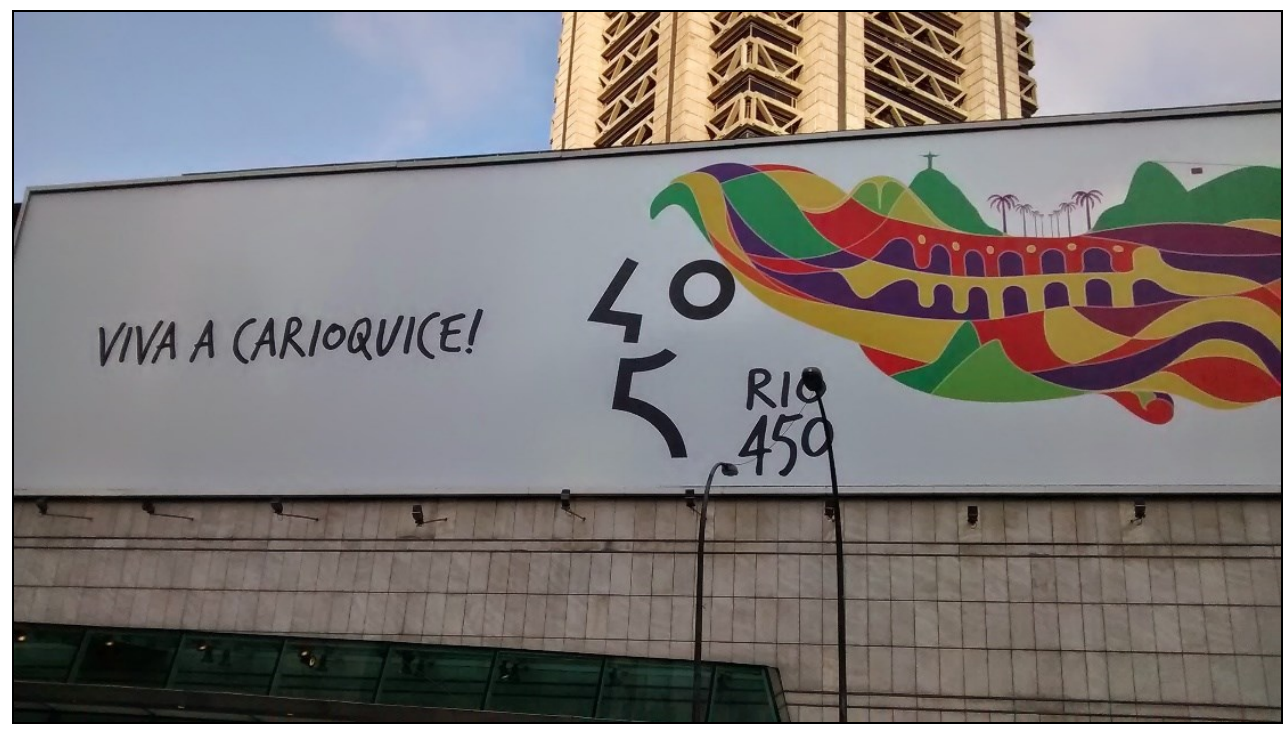

Fonte: Acervo pessoal

As UPPs exercem papel fundamental neste processo. Com a redução dos confrontos entre policiais e grupos armados, as favelas tornaram-se ponto turístico obrigatório para visitantes nacionais e estrangeiros, à procura "tanto o fascínio e o horror frente aos imaginários da favela violenta e desregrada quanto o fascínio e o glamour da favela 'comunidade' estilizada ou autêntica" (JAGUARIBE, 2011, p. 343). É nas favelas onde se pode participar de uma roda de samba, entretenimento tradicional dos moradores das favelas; apreciar a exuberante geografia 
carioca a partir de um ponto de observação pouco comum aos cartões postais tradicionais, ou mesmo degustar o que o discurso midiático elege como uma saborosa iguaria típica do país: o trivial prato de arroz, feijão, bife e batatas fritas:

O sacrifício não foi nada para o jornalista sueco HakanForsberg que ficou maravilhado com a paisagem e o sabor do simples arroz com feijão, bife e fritas que comeu. "A subida foi compensada pela bela paisagem e pela comida deliciosa", disse enquanto saboreava o almoço (COSTA, 2010). ${ }^{11}$

\section{LEGITIMAÇÃO DISCURSIVA}

As mudanças ocorridas, no entanto, afetaram também a maneira como o carioca passou a se relacionar com a cidade. As UPPs instaladas em bairros estratégicos do Rio criaram favelas de elite, onde os valores dos imóveis e os serviços cobrados pelo Estado e pela iniciativa privada dispararam, levando muitos dos antigos moradores a deixarem suas casas rumo a bairros mais afastados do centro da cidade. O fenômeno da "gentrificação" (PAIVA e SODRÉ, 2004) fez com que locais outrora frequentados por uma população de menor poder aquisitivo fossem tomados por investimentos privados para usufruto de um público mais abastado. A palavra tem origem do inglês gentry, que significa, em tradução livre, "gente boa", "gente fina".

Trata-se do que os especialistas chamam de imagem-making, isto é, fazer boa imagem da cidade para que os negócios prosperem. O Rio em si mesmo já é uma boa "base imagística" poderosa, tanto para o exterior quanto para o resto do Brasil. Veja-se a estátua do Cristo Redentor, que caracteriza há sete décadas a cidade: existem 111 réplicas da estátua de norte a sul do país (PAIVA e SODRÉ, 2004, p. 85).

Muitas das vezes, a estratégia utilizada para "gentrificar" uma região da cidade é a instalação de equipamentos de cultura, esporte, lazer e entretenimento, que gozam de grande popularidade e podem justificar a desapropriação de famílias, remoção de casas de baixo valor imobiliário ou o deslocamento de pessoas em situação de rua. Exemplo é o empreendimento "Porto Maravilha", erguido na zona portuária da cidade, antes habitada pela população de baixa renda, mas que, nos últimos anos, com a construção do Museu de Arte do Rio (MAR) e do

${ }^{11}$ COSTA, A.C. Com pratos fartos e preços convidativos, bares de comunidades com UPP querem atrair turistas. $\mathbf{O}$ Globo Online. Rio de Janeiro, 9 de outubro de 2010. Disponível em:

$<$ http://oglobo.globo.com/rio/rioelegal/mat/2010/10/09/com-pratos-fartos-precos-convidativos-bares-decomunidades-com-upp-querem-atrair-turistas-922756117.asp $\geq$. Acesso: 1 out. 2015.

Comun. \& Inf., Goiânia, GO, v. 18, n. 02, p. 180-197, jul./dez. 2015

Caderno Casadinho Procad UFG-UFRJ 
Museu do Amanhã, e de edifícios de salas comerciais de alto padrão e valor especulativo, passou a deixar gradativamente a região.

Revitalizar, restaurar, modernizar. São diversos os eufemismos utilizados pela mídia comercial para traduzir ao grande público o processo em curso no Rio de Janeiro. O discurso midiático tende a privilegiar um enquadramento em que o grande público é levado a crer que a cidade do Rio de Janeiro passa por um momento de transformações apenas positivas, com o surgimento de oportunidades de negócios, a partir da realização dos megaeventos. De acordo essa perspectiva, um dos principais fatores que possibilita essas mudanças é a política de Segurança Pública, que reduziu o índice de homicídios nas favelas, permitindo assim, o maior movimento turístico, investimentos públicos e privados, geração de empregos, criação de políticas públicas e outros benefícios em áreas da cidade outrora consideradas perigosas. Entretanto, se por um lado a narrativa midiática agenda a questão da Segurança Pública e dos megaeventos, a partir de um enquadramento de lei e ordem e de oportunidades de investimentos, por outro, tende a silenciar sobre a violação de direitos humanos, o ataque às liberdades civis e o cerceamento do acesso à cidade formal por que passa parte da população residente em favelas ${ }^{12}$ e bairros distantes do centro comercial da cidade.

No caso do Rio de Janeiro, o processo de "gentrificação", ou revitalização (conforme o gosto), não se dá apenas por meio da ocupação policial nas favelas e da criação de novas linhas de metrô e ônibus e da modernização $o^{13}$ da zona portuária, mas também pela remoção de favelas que dão lugar a equipamentos esportivos e corredores de ônibus, da construção de muros nas comunidades, da chegada de grandes empresas às favelas, em substituição ao pequeno comércio, ou da substituição de antigos moradores por recém-chegados com poder aquisitivo mais elevado. No entanto, nas páginas de $\mathbf{O}$ Globo, as consequências positivas deste processo são mais facilmente encontradas, privilegiando o discurso oficial de uma cidade em recuperação econômica, política e cultural, como é possível observar logo na capa da edição do dia 27 de outubro de 2013 (Figura 2). Os aspectos negativos são silenciados ou noticiados apenas de

\footnotetext{
12 De acordo com dados do Censo 2010, do IBGE, a capital fluminense tem 1,3 milhão de habitantes vivendo nas 763 favelas da cidade, o que representa $22 \%$ dos cerca de 6,3 milhões de moradores. Se considerarmos que apenas 38 favelas receberam UPPs até agora, precisamos admitir que a política de governo acaba por criar favelas de elite, situadas próximas aos bairros mais ricos da cidade, e negligencia sobre a situação de todas as demais áreas, localizadas em bairros afastados do chamado cinturão de segurança, onde reside a maior parte da população carioca.

${ }^{13}$ Outra palavra comumente utilizada para se referir ao mesmo processo.
}

Comun. \& Inf., Goiânia, GO, v. 18, n. 02, p. 180-197, jul./dez. 2015 
maneira superficial e passageira, apresentados como uma consequência inevitável, um mal necessário à população da cidade.

Figura 2 - "Economia, eventos e UPPs reinventam os bairros do Rio"

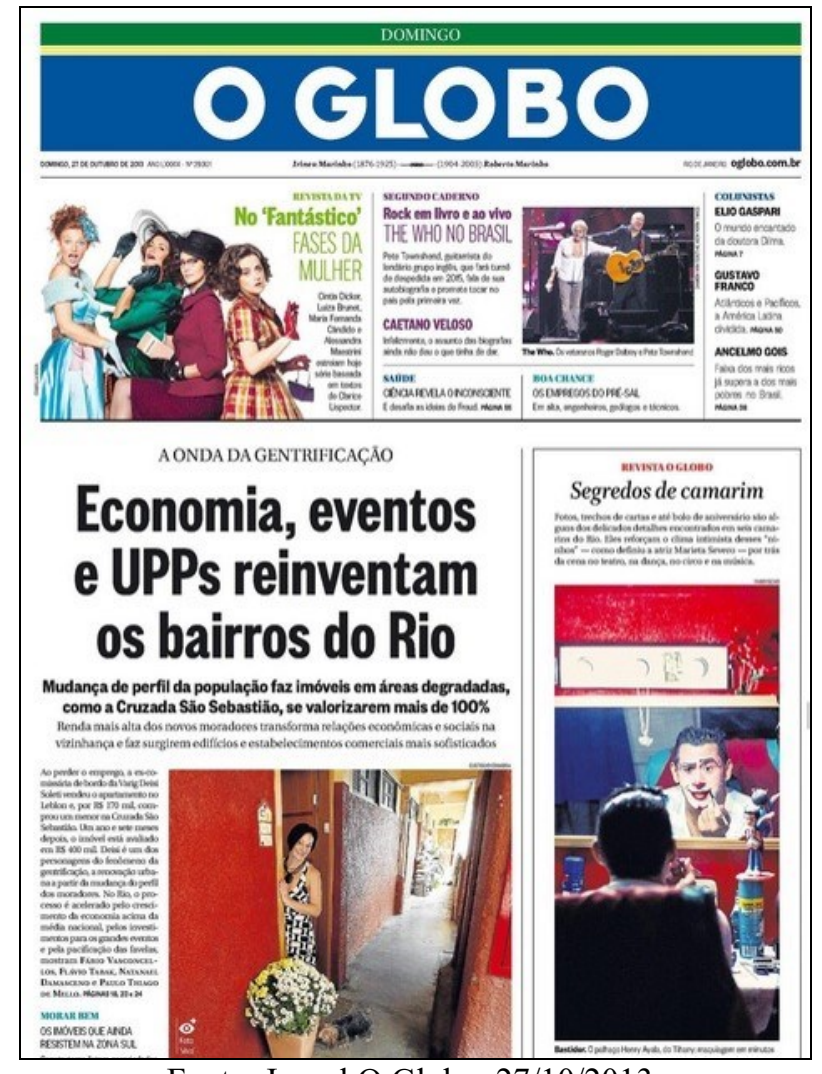

Fonte: Jornal O Globo, 27/10/2013.

Nas páginas internas, um anúncio de página dupla informa sobre "o lançamento imobiliário do ano", às margens da Lagoa de Marapendi, na Barra da Tijuca. A matéria sobre a gentrificação tem início na página 18 com o título "Novo retrato da metrópole: bons ventos da economia no estado atraem novos moradores e mudam a cara dos bairros" ${ }^{14}$. Na matéria seguinte, o título anuncia que "imóveis na Cruzada se valorizam em até 135\%", em referência ao conjunto habitacional, localizado no Leblon, construído pela Arquidiocese do Rio, na década de 1950, após um incêndio que devastou a favela da Praia do Pinto. A tônica do texto são as oportunidades que se abriram nas favelas:

\footnotetext{
${ }^{14}$ Novo retrato da metrópole: bons ventos da economia no estado atraem novos moradores e mudam a cara dos bairros. O Globo. Rio de Janeiro, 27 de outubro de 2013, editoria Rio, p. 18.
} 
Quando saí do meu apartamento, senti os olhares de quem dizia 'ih, faliu!'. Sei que me viam como uma derrotada. Mas minha visão é outra. É a de empreendedora. Comprei o apartamento há um ano e sete meses por R\$170 mil. Hoje, depois da reforma completa, está avaliado em R\$ 400 mil (VASCONCELOS, 2013, p. 23.). ${ }^{15}$

Os aspectos negativos da "gentrificação" aparecem apenas na página 24. Mesmo assim, o Globo os apresenta quando o processo relatado acontece em Istambul, na Turquia ${ }^{16}$. “[...] os antigos moradores, muitas vezes de minorias étnicas, têm que deixar suas casas, demolidas para dar lugar a novos empreendimentos, inacessíveis a seus bolsos" ${ }^{17}$. Em outro trecho, a reportagem relata um episódio muito comum no Rio:

A transformação urbana suscitou várias críticas, tanto de urbanistas quanto da população afetada. O governo, que quer fazer de Istambul uma cidade cosmopolita, rivalizando com Londres e Nova Iorque, argumenta que as pessoas estão melhores em imóveis novos do que em habitações insalubres. O Ministério do Desenvolvimento Imobiliário da Turquia (Toki, pela sigla em turco), responsável pela construção de moradias populares, ressalta oferecer imóveis ao alcance do bolso da população de baixa renda. Mas esses imóveis, ressaltam os críticos, são sempre distantes do Centro de Istambul (SANTOS,2013, p. 24). ${ }^{18}$

\section{REPRESENTAÇÕES: VÍTIMAS X BANDIDOS}

Ainda que algumas favelas da zona sul da cidade tenham passado a receber novos visitantes e se tornado pontos turísticos cobiçados e valorizados economicamente, sua representação social ainda é a mesma do século XIX, quando a obra "Os sertões", de Euclides da Cunha, serviu como mito de origem para os estudos sociológicos sobre este conjunto de habitações. De acordo com Valladares (2005), o povoado de Canudos "corresponde àquela vislumbrada pelos primeiros visitantes da favela do Rio, quando transpuseram em suas descrições a dualidade 'litoral versus sertão' para a dualidade 'cidade versus favela'." (VALLADARES, 2005, p. 23).

Desde o seu surgimento, no século XIX, as favelas eram motivo de "sobressalto das famílias" (ZALUAR; ALVITO, 2003, p. 8), consideradas pela imprensa "núcleo de desagregação

\footnotetext{
${ }^{15}$ VASCONCELLOS, [et al]. Cidade em transe. Imóveis na Cruzada se valorizam em até $135 \%$. Localização privilegiada de áreas da zona sul atrai compradores com maior poder aquisitivo. O Globo. Ed. Rio. 27 de outubro de 2013, p. 23.

${ }^{16}$ SANTOS, C. Shoppings de luxo, no lugar de comércio local: Reforma urbana provoca deslocamento de minorias étnicas do centro para áreas do subúrbio. O Globo. Ed. Rio. 27 de outubro de 2013. p. 24.

${ }^{17}$ Idem

${ }^{18}$ Idem

Comun. \& Inf., Goiânia, GO, v. 18, n. 02, p. 180-197, jul./dez. 2015 
social" e local onde "malandros levantam barracos da noite para o dia, prejudicando a vida dos trabalhadores" ${ }^{\prime 19}$ e objeto de preocupação das autoridades instituídas, que, durante boa parte do século XX se ocuparam em tentar removê-las. Entre os anos 1940 e 1960, políticas públicas empreendidas levaram ao deslocamento de cerca de 100 mil pessoas de favelas da zona sul para localidades remotas, onde foram criados conjuntos habitacionais com nomes que remetiam a um imaginário idílico, como Vila Aliança, Vila Kennedy, Vila Esperança e Cidade de Deus, não obstante a carência de infraestrutura de transporte, saneamento básico, saúde, educação e serviços. O jornalista Carlos Lacerda denominou de Batalha das Favelas a série de artigos publicados nos jornais da época, em que reivindicava a extinção dos tais "aglomerados subnormais" (VALLADARES, 2005), conferindo a legitimação discursiva necessária para o êxito da política pública que ele mesmo executaria anos mais tarde, quando exerceu o cargo de governador do estado da Guanabara (1960-1965).

Da mesma forma em que as favelas são percebidas como locais a serem evitados pelas classes média e alta, seus moradores também sofrem com o "estigma" (GOFFMAN, 1980) por habitarem um local, presumidamente, de carência e criminalidade. De acordo com Vaz; Baiense (2011), se até os anos 1980, a maior parte das notícias analisadas tinham como enquadramento predominante a precariedade de Emprego (19\%), Habitação (19\%) e Saúde (8\%) - configurando assim "a favela como lugar de carência" (VAZ; BAIENSE, 2011, p. 4) - a partir dos anos 2010, em um universo de 90 matérias analisadas, 38\% representavam as favelas como território sitiado e $29 \%$ como fonte de violência - tornando predominante, assim, o enquadramento Violência/Criminalidade.

Assim, de acordo com a representação midiática, é na favela onde encontra-se o perfil típico da "sujeição criminal" (MISSE, 2008), qual seja, o jovem, negro e pobre, em quem costuma-se colar, de maneira indissociável, a identidade de "bandido", aquele "que carrega o crime em sua própria alma, [...] que sempre cometerá crimes, [...] um sujeito perigoso, um sujeito irrecuperável, alguém que se pode desejar naturalmente que morra, que pode ser morto, que seja

\footnotetext{
${ }^{19}$ VASCONCELLOS, et al.Cidade em transe. Imóveis na Cruzada se valorizam em até $135 \%$. Localização privilegiada de áreas da zona sul atrai compradores com maior poder aquisitivo. O Globo. Ed. Rio. 27 de outubro de 2013, p. 23

${ }^{19}$ SANTOS, C. Shoppings de luxo, no lugar de comércio local: Reforma urbana provoca deslocamento de minorias étnicas do centro para áreas do subúrbio. O Globo. Ed. Rio. 27 de outubro de 2013. p. 24.
}

Comun. \& Inf., Goiânia, GO, v. 18, n. 02, p. 180-197, jul./dez. 2015

Caderno Casadinho Procad UFG-UFRJ 
"matável"” (MISSE, 2008: p. 21). O bandido é percebido como o causador do sofrimento das "vítimas virtuais" (VAZ, 2009), ou o cidadão de bem, o trabalhador, o contribuinte de impostos ao Estado, ou seja, o indivíduo das classes média e alta. O indivíduo identificado no perfil da sujeição criminal deve ser punido e alijado do convívio social, de acordo comas políticas penais retributivas, segundo as quais os investimentos na recuperação de infratores passaram a ser “consideradas luxos onerosos, que os contribuintes trabalhadores não podiam mais sustentar" (GARLAND, 2008: p. 182).

No Brasil, o resultado dessa política pode ser notado no Levantamento Nacional de Informações Penitenciárias (Infopen) ${ }^{20}$, divulgado pelo Ministério da Justiça, em junho de 2015, contabiliza 607.731 pessoas privadas de liberdade no Brasil até junho de 2014, o equivalente a 300 presos para cada 100 mil habitantes no país. Chama a atenção ainda que o número de vagas é de 376.669 pessoas, o que representa um déficit de 231.062 vagas e uma taxa de ocupação de 161\%. Quanto ao perfil das pessoas privadas de liberdade, 67\% são negros e 80\% estudaram até, no máximo, o ensino fundamental. Em relação aos crimes cometidos, o tráfico de entorpecentes é o crime que mais prende, com $27 \%$. Outro sintoma que denuncia uma política de extermínio e privação de liberdades pelo Estado contra a população negra e pobre são os números da Anistia Internacional, segundo os quais, das 56 mil pessoas assassinadas no Brasil em 2012, 30 mil eram jovens entre 15 e 29 anos e, desse total, 77\% eram negros ${ }^{21}$ - observando, naturalmente, que o déficit de nosso passado escravocrata legou à população negra brasileira um presente de precariedade nas favelas.

\section{CONSIDERAÇÕES FINAIS}

$\mathrm{Na}$ presente pesquisa em andamento, foi possível verificar até aqui uma prevalência de um enquadramento por parte das matérias publicadas no jornal O Globo sobre as Unidades de Polícia Pacificadora, entre 2008 e 2012, que reivindica maior lei e ordem do poder público para prevenir e conter a violência na cidade. As UPPs são apresentadas como a solução para o problema por ter reduzido os confrontos entre policiais e grupos armados de comerciantes de

\footnotetext{
${ }^{20}$ Disponível em: <http://www.justica.gov.br/seus-direitos/politica-penal $\geq$. Acesso em: 2 out 2015.

${ }^{21}$ Anistia Internacional. Disponível em: $<$ https://anistia.org.br/campanhas/jovemnegrovivo/>. Acesso em: 2 out. 2015.
}

Comun. \& Inf., Goiânia, GO, v. 18, n. 02, p. 180-197, jul./dez. 2015 
entorpecentes. As mortes dos moradores decorrentes de ações policiais, relatos de abusos de autoridade, intimidações e achaques são retratados de forma secundária e tacitamente justificados - por meio de estatísticas e declarações oficiais - sob o pretexto de que se tratam de "casos isolados", "acidentes de percurso" ou algo menor frente ao grande objetivo que seria a pacificação completa da cidade. Ou o que Batista (2012) denomina de sopa de pedra de Pedro Malasartes: "aguentem as mortes, as balas perdidas, as invasões de domicílio, as revistas para entrar e sair de casa... o melhor está por vir!” (BATISTA, 2012: p. 92).

A partir de 2013, portanto no contexto da proximidade dos megaeventos esportivos internacionais, as UPPs ganham uma nova dimensão nas reportagens: a da oportunidade. Tanto para o morador da favela que pode vir a ter melhorias em sua comunidade - advindas não apenas da segurança, mas também da oferta de outros serviços que passarão a existir a partir da presumida pacificação - como para o morador ou investidor "do asfalto", que poderá conhecer e se divertir em um local onde outrora não frequentava e mesmo investir em um imóvel ou um negócio a um preço menor do que o habitual. No entanto, também neste período temporal o enquadramento predominante relega a uma importância menor tanto as violações de direitos e liberdades civis dos moradores das favelas, como o êxodo de moradores para outras localidades, devido ao surgimento de uma favela inflacionada. Ambos os efeitos são tratados igualmente como "males necessários".

Desta maneira, nossa hipótese para o prosseguimento desta pesquisa é de que o discurso midiático do principal jornal da cidade e do estado legitima a política de Segurança Pública que serve como fundamento para um projeto de cidade onde a cidadania se dá por meio da fruição estética e do consumo. Aqueles que detém mais recursos financeiros têm acesso à chamada "Cidade Maravilhosa", enquanto a outros, sem tantas condições materiais, está reservada a “cidadania”, a "cidadania possível” (BATISTA, 2003), ou ainda a "cidadania negativa, enunciada por Nilo Batista, que se restringe ao conhecimento e exercício dos limites formais à intervenção coercitiva do Estado" (op. Cit.: p. 102).

\section{REFERÊNCIAS}

5X PACIFICAÇÃO. Produção de Renata Almeida Magalhães e Carlos Diegues. Direção de Cadu Barcellos, Luciano Vidigal, Rodrigo Felha, Wagner Novais. Rio de Janeiro, Brasil, 2012. (86min.). Disponível em:<https://www.youtube.com/watch?v=1QGAjDUtozY>. Acesso em: 02 out. 2015. 
ALMEIDA, A. G.; NAJAR, A. L. Cidade Maravilhosa e Cidade Partida: notas sobre a manipulação de uma cidade deteriorada. Rua [online], Campinas (SP), v. 1, n. 18, 2012. Disponível

em: $<$ http://www.labeurb.unicamp.br/rua/pages/home/capaArtigo.rua?id=127>. Acesso em: 02out. 2015.

ANISTIA INTERNACIONAL (Brasil). Disponível em

$<$ https://anistia.org.br/campanhas/jovemnegrovivo/>. Acesso em: 2 out. 2015.

BATISTA, V. M. O Alemão é muito mais complexo. In: BATISTA, V. M (Org.) Paz armada. Rio de Janeiro: Revan, 2012.

BATISTA, V. M. O medonacidade do Rio de Janeiro: dois tempos de uma história. Rio de Janeiro: Revan, 2003.

BECKETT, K. Making crime pay: law and order in contemporary american politics. New York; Oxford: Oxford University Press, 1997.

COMAROFF, J. L. J. Ethnicity, Inc. University of Chicago Press: Chicago, 2009.

COSTA, A. C. Com pratos fartos e preços convidativos, bares de comunidades com UPP querem atrair turistas. O Globo Online. Rio de Janeiro, 9 de outubro de 2010. Disponível em:

$<$ http://oglobo.globo.com/rio/rioelegal/mat/2010/10/09/com-pratos-fartos-precos-convidativos-bares-decomunidades-com-upp-querem-atrair-turistas-922756117.asp>. Acesso: 1 out. 2015.

GARLAND, D. A cultura do controle: crime e ordem na sociedade contemporânea. Rio de Janeiro: Revan, 2008.

GOFFMAN, E. Estigma. Rio de Janeiro: Editora Zahar, 1980.

HOHLFELDT, A. Hipóteses contemporâneas de pesquisa em Comunicação. In: HOHLFELDT, A. et al (Org.). Teorias da comunicação: conceitos, escolas e tendências. Petrópolis: Vozes, 2001.

JAGUARIBE, B. Imaginando a "cidade maravilhosa": modernidade, espetáculo e espaços urbanos.

Revista Famecos, Porto Alegre, v. 18, n. 2, p. 327-347, mai./ago. 2011.

BRASIL. Ministério da Justiça. Departamento Penitenciário Nacional. Levantamento Nacional de Informações penitenciárias. Brasília, DF, 2014. 148 p. Disponível em: <http://www.justica.gov.br/seusdireitos/politica-penal>. Acesso em: 2 out. 2015.

MISSE, M. Crime, sujeito e sujeição criminal: aspectos de uma contribuição analítica sobre a categoria “bandido". Revista Lua Nova, São Paulo, n. 79, p. 15-38, 2010.

MISSE, M. Sobre a construção social do crime no Brasil: esboços de uma interpretação. In: MISSE, M. Acusados e acusadores: estudos sobre ofensas, acusações e incriminações. Rio de Janeiro: Editora Revan/Faperj, 2008.

NITAHERA, A. Comitê critica reforma do Maracanã e remoção de famílias no período da copa. EBC Agência Brasil, Rio de Janeiro, 2014. Disponível em: <http://agenciabrasil.ebc.com.br/geral/noticia/201412/comite-critica-reforma-do-maracana-e-remocao-de-familias-no-periodo-da-copa>. Acesso em: 24 mai. 2015 . 
NOVO retrato da metrópole: bons ventos da economia no estado atraem novos moradores e mudam a cara dos bairros. O Globo, Rio de Janeiro, 2013.

PAIVA, R.; SODRÉ, M. Cidade dos artistas: cartografia da televisão e da fama no Rio de Janeiro. Rio de Janeiro: Mauad, 2004.

PEREIRA, P. Segurança para quem? O discurso midiático sobre as Unidades de Polícia Pacificadora. 2012. 120f. Dissertação (Mestrado em Comunicação e Cultura) - Universidade Federal do Rio de Janeiro, Rio de Janeiro, Brasil, 2012.

RODRIGUES. N. À sombra das chuteiras imortais: crônicas de futebol. São Paulo: Companhia das Letras, 1993.

SANTOS, C. Shoppings de luxo, no lugar de comércio local: reforma urbana provoca deslocamento de minorias étnicas do centro para áreas do subúrbio. O Globo, Rio de Janeiro, 2013.

SANTOS, J. F. dos. Feliz 1958: o ano que não devia terminar. 4. ed. Rio de Janeiro: Record, 1998.

SANTOS, M. As cidades mutiladas. In: SÃO PAULO (Estado). Secretaria da Justiça e da Defesa da Cidadania. São Paulo: IMESP, 1997.

TERKILDSEN, N.; SCHNELL, F. How media frames moves public opinion: analysis of women's movement. Political Research Quarterly. v. 50, n. 4, p. 879-900, 1997.

VALLADARES, L. P. A invenção da favela: do mito de origem à favela.com. Rio de Janeiro: Editora FGV, 2005.

VASCONCELLOS, P. (et al.). Cidade em transe: imóveis na cruzada se valorizam em até 135\%: localização privilegiada de áreas da zona sul atrai compradores com maior poder aquisitivo. O Globo, Rio de Janeiro, p. 23-27 de outubro de 2013.

VAZ, P. Vítima virtual a mídia. In: VIGILÂNCIA, SEGURANÇA E CONTROLE SOCIAL. 2009, Curitiba. Anais... Curitiba: PUCPR, 2009. p. 51-69.

VAZ, P.; BAIENSE, C. Mídia e enquadramento: as representações da favela na virada do século XXI. VIII ENCONTRO NACIONAL DE HISTÓRIA DA MÍDIA, 8., 2011, Guarapuava. Anais... Guarapuava, PR: Unicentro, 2011.

ZALUAR, A.; ALVITO, M. (Orgs.). Um século de favela. 3. ed. Rio de Janeiro: Editora FGV, 2003.

Comun. \& Inf., Goiânia, GO, v. 18, n. 02, p. 180-197, jul./dez. 2015

Caderno Casadinho Procad UFG-UFRJ 